\title{
Types of Catalysis \& its Applications
}

\author{
Ananya Guduru* \\ Department of Biotechnology, Jawaharlal Nehru Technological University Hyderabad, Hyderabad, India
}

\begin{abstract}
The world is running for the enhancements in the industrial sector. In the chemical and industrial sector catalysis plays a vital role, it also helps in the economic growth. Industrial sector is the major cause for the development in the economy. Catalysis is a chemical process for the development of useful byproduct. The process of modifying the chemical reaction using catalyst is known as catalysis. Catalysts reduces time consumption as it uses less active energy and process the things faster than the standard chemical reactions. Catalysis and its catalysts type and the developments is the aim of the study.
\end{abstract}

Keywords: Catalysis, Chemical reactions, Industrial process, Heterogeneous, Homogeneous

\section{Introduction}

In the modern scientific era, catalysis occupies an important place in both academic research and industry with considerable potential of applications in everyday life including fine chemicals, agrochemicals (synthesis of pesticide, fertilizers), pharmaceuticals, petroleum (in oil refining, biofuel production, fuel cells etc.), polymers (plastics, adhesives), electronics, and environmental clean-up (limiting the emission of noxious gases from automobiles and stationary sources, removal of $\mathrm{CO}$ and odors from indoor air, and cleaning of groundwater). According to the recently published report entitled "Catalyst Market - Global Industry Size, Share, Growth, Trends and Forecast 2012 - 2018" the worldwide market value of catalyst was at 19.2 billion USD per annum in 2014 and is expected to reach USD 24.1 billion by 2018. The use of catalysts technology is well known from ancient time, although the concept of catalysis was not clear at that time. This includes the formation of alcohol from sugar by fermentation, synthesis of soap by hydrolysis of animal fat using caustic potash, conversion of alcohol to ether catalyzed by sulfuric acid. In 1836, the term 'catalysis' was coined by Swedish chemist Berzillius, and Ostwald in 1895 scientifically explained it as: "a catalyst accelerates a chemical reaction without affecting the position of the equilibrium." In 1909, Ostwald was awarded the noble prize for his pioneering work in this field [1].

Catalyzed reactions can be broadly classified into two categories: heterogeneous and homogeneous. In heterogeneous reactions, the phase of catalyst is different from that of reactants, i.e. solid, liquid or gas [2,3]. However, it can also mean that the miscibility of the catalyst is different from the reaction mixture too. With homogeneous reactions, the catalyst and other reactants are the same phase and are miscible with one another. The type of reaction will have implications for the recovery of the catalyst post-reaction, which is a cumbersome method comparing to heterogeneous catalysts where the reaction mixture is filtered.

\section{Short Note}

\section{Types of catalysis}

Catalysis has been classified into 4 types

1. Homogeneous

2. Heterogeneous

As the process of the catalysis is very significant, the catalysis types are also very significant.

\section{Homogeneous}

Occupying the same phase (gas \& liquid) as reactants is known as homogenous catalysis. It allows larger interactions with the mixtures of reactants [4].

*Correspondence to: Ananya Guduru, Department of Biotechnology, Jawaharlal Nehru Technological University Hyderabad, India, E-mail: ananyareddy26@ ymail.com

Citation: Guduru A (2020) Types of Catalysis \& its Applications. J Catal Chem Eng Adv 7(1): 102. DOI: https://doi.org/10.47275/2693-7182-102.

Received: May 01, 2020; Accepted: June 01, 2020; Published: July 15, 2020

Copyright: $\odot 2020$ Guduru A. This is an Open Access article distributed under the terms of the Creative Commons Attribution 4.0 International License (CCBY) (http://creativecommons.org/licenses/by/4.0/) which permits commercial use, including reproduction, adaptation, and distribution of the article provided the original author and source are credited. 
Homogeneous catalysis plays an important role in the simple and complex molecules synthesis, including drug compounds, natural products, and agrochemicals. It has made it a crucial tool for the modification of biomolecules, such as carbohydrates (sugars), amino acids, peptides, nucleosides, nucleotides, and steroids. Development of new molecules of biological relevance at a rapid rate relative to the number of available synthetic methods [5].

\section{Heterogeneous}

Existence of catalysis in different phases than the reaction mixture is known as Heterogeneous catalysis, it is solid and reactant of gases and the rate limit occurs at the solid surface.Thus,it is also referred to as surface catalysis [6]. Heterogeneousdominate major industrial processes as it tends for easy separation of products and recovery of catalyst. Heterogeneous catalysts may be used as fine particles, powders, granules. These catalysts may be deposited on the solid support (supported catalysts), or used in bulk form (unsupported catalysts).

\section{Applications}

To increase the reaction rate without getting consumed in the process, substance catalyst can be added. In the biochemical reaction enzymes are protein that act as catalysts. Catalysts typically speed up a reaction by reducing the activation energy or changing the reaction mechanism. Common types of catalysts include enzymes, acid-base catalysts, and heterogeneous (or surface) catalysts [7]. In industrial and pharmaceutical processessolvent extraction, filtration, nano filtration, chemical precipitation, and adsorption are catalyst recovery techniques typically employed. Nanofiltration recovery is used only with homogeneous processes and catalysts are immediately re-used in the liquid phase. Thus, nanofiltration is not principally amenable to incineration and recovery of the catalysts for future use.

Adsorptive recovery techniques can include materials such as activated carbon and ion exchange resins to recover either homogeneous catalysts, or homogeneous ligand and/or leachate. With a homogeneous catalyst, the carbon or resin will selectively absorb the catalyst. The catalyst is then stripped from the adsorbent for reuse or sent to a recovery specialist for incineration and recovery. For a homogeneous ligand and/or leachate, a fragment of a heterogeneous catalyst is shed and then dissolved in the phase where the chemical transformation is taking place. The catalyst is filtered from the batch and the ligand and and/or leachate that remains in solution is removed via resin or carbon treatment [8].

\section{References}

1. An Overview of Different Types of Catalysts.

2. Sabatier P, Sendrens JB (1900) Hydrogenation of ethylene in presence of different metals. ComptesRendusHebdomadais des Seances. del'Academie des science 130: 1781.

3. Sabatier P, Sendrens JB (1899) Action of hydrogen on acetylene in presence of nickel. ComptesRendusHebdomadais des Seances. de l'Academie des science 128: 1173.

4. Homogeneous Catalysis.

5. Shelke YG, Yashmeen A, Gholap AVA, Gharpure SJ, Kapdi AR (2918) Homogeneous Catalysis: A Powerful Technology for the Modification of Important Biomolecules. Chem AsianJ 13(20): 2991-2991-3013.https://doi.org/10.1002/asia.201801020

6. Heterogeneous catalysis.

7. A kinetics thought experiment.

8. Rahman R, Uahengo V, Likius D (2017) Green chemistry concept: Applications of catalysis in pharmacuetical industry. Glob Drugs Therap 2(4): 1-6.https:/doi.org/10.15761/ GDT. 1000130 